\title{
Laban e Freire: Entre o velho e o novo mundo
}

\author{
Isabel Marques \\ Instituto Caleidos / São Paulo - SP \\ E-mail: caleidos2@gmail.com
}

\section{Resumo}

Esse artigo busca estabelecer diálogos entre Rudolf Laban e Paulo Freire partindo das discussões propostas nos livros "Domínio do Movimento" (obra síntese de Laban, 1950) e "Pedagogia do Oprimido" (obra inicial de Paulo Freire, 1968). Tanto o trabalho de Laban quanto de Freire foram, no século $X X$, referências para a dança e para a educação, respectivamente, e continuam influenciando e desafiando o fazer/pensar de artistas e educadores nos dias de hoje. Esse artigo busca aproximar esses dois autores discutindo relações entre suas visões de dança, educação e mundo.

\section{Abstract}

This article seeks to establish dialogues between Rudolf Laban and Paulo Freire having as a starting point the discussions held in the books "Mastery of Movement" (which synthetizes the work of Laban) and "Pedagogy of the Opressed" (Freire's initial masterpiece). Both, the work of Laban and Freire, stand as landmarks for dance and education in the 20th century and continue to be influential for artists and educators to think, make and do dance nowadays. This article seeks to bring together the authors' ideas in order to build a net of relationships between their ways of understanding dance, education and the world around us.

Dance. Education. Social Crisis. Society. 


\section{Primeiramente}

Vivemos uma crise sanitária e política sem precedentes. A pandemia da Covid 19 colocou lentes de aumento sobre nossas crenças, comportamentos, escolhas, problemas e modos de vida. A mim, reacendeu a pergunta que não cala (há mais de 20 anos): o que o ensino de dança tem a ver com tudo isso?

\section{Outros tempos, questões parecidas}

Quando a crise era de outra ordem - mas talvez tão profunda quanto a que estamos nos deparando hoje - tive o grande privilégio de trabalhar como assessora na área de Dança na Secretaria Municipal de Educação de São Paulo (SME/SP) na gestão de Paulo Freire ${ }^{1}$. A diferença é de que naquela época havia esperança: quando Luíza Erundina assume a prefeitura de São Paulo em 1989, o país renascia de uma ditadura militar com as portas abertas para a ousa$\mathrm{dia}^{2}$, para novos projetos que pautavam e fortaleciam a democracia. Hoje, ao contrário disso, menos esperançosos e mais acuados, nos apegamos aos fiapos que ainda existem de uma democracia encurralada para continuar construindo o país que Paulo Freire desejou: um país em que haja justiça, ética e belezura.

Durante a gestão Paulo Freire na SME-SP, a Dança foi introduzida como disciplina obrigatória na cidade de São Paulo, juntamente com outras linguagens artísticas. Ousávamos propor, já em 1991, que Arte é conhecimento, não atividade meio3; que a leitura da arte - aliado ao fazer artístico - também é conteúdo de Arte; e enfim, nos passos e propostas de Ana Mae Barbosa, que o ensino de Arte deveria ser

1 Gestão Luiza Erundina, de 1989-1993.

2 Fruto do trabalho coletivo de assessores da SME/ SP foi organizado o livro que trata dessa ousadia. Vide Pontuschka (1993). Vide também Freire; Shor (1986).

3 Nunca é demais relembrar que na época vigorava a Lei 5692/71 em que a Arte era apenas atividade curricular. contextualizado ${ }^{4}$, o que vinha ao encontro das propostas de Paulo Freire para a Rede Municipal de Ensino.

A relação Laban-Freire começou a ser estabelecida quando propus que os referenciais de Laban deveriam sustentar a proposta de dança nas escolas do município que, por sua vez, dialogaria com a proposta curricular da rede: a Interdisciplinaridade via Tema Gerador. Naquela época, compreendi, mesmo que de forma embrionária, que as propostas freirianas dariam maior consistência política e social aos estudos de Laban. Ou seja, entendi que os elementos estruturais da dança propostos por Laban - a Coreologia - floresceriam quando à luz da problematização, da dialogicidade e da crítica social que edificam a pedagogia freiriana ${ }^{5}$. Outras perguntas surgiam: como abordar Temas Geradores propostos por Paulo Freire na perspectiva da dança? Ou, que contribuições a dança tinha a dar para problematizar, dialogar, agir e transformar a realidade social? ${ }^{6}$ Grosso modo, mesmo não explicitamente, já buscava relações entre as propostas de Rudolf Laban e de Paulo Freire - um diálogo que, ao longo dos anos, se revelou bastante profícuo para repensarmos e ressignificarmos as relações entre o ensino de Dança e a sociedade ${ }^{7}$.

Esse artigo busca aproximar esses dois autores discutindo relações entre suas visões de dança, educação e mundo na tentativa de revisitá-las diante da crise atual que abala as estruturas fundantes do século XX. Forjar um diálogo entre arte e educação hoje tendo Laban e Freire como interlocutores é uma tentativa de buscar novas rotas de ação que sejam multifacetadas e abertas, ao mesmo tempo que afetuosas e políticas.

\section{Nessa época foi introduzido no currículo escolar do mu- nicípio de São Paulo a Abordagem Triangular proposta por Ana Mae Barbosa. Vide São Paulo (1991).}

5 Sobre a relação entre Coreologia e tema gerador vide Marques (1998, 2010a).

6 Vide Marques (1995).

7 Essa experiência embrionária foi, em 1996, desenvolvida e ampliada em minha pesquisa de Doutorado defendida na FEUSP e publicada em livro. Vide Marques (1999). 
Proponho aqui uma conversa entre Laban artista e Freire educador, mesmo tendo sido Laban um educador e Freire um primoroso leitor de arte. Meu foco nessas páginas se encontra em discutir os princípios de Laban do ponto de vista da criação artística, tendo como premissa inicial que processos artísticos são, em si, educacionais. Nesse encontro intrínseco entre dança e educação, o trabalho de Freire tem muito a contribuir para que os princípios fundantes da arte do movimento propostos por Laban possam ser compreendidos desde uma perspectiva não universalizante e/ou colonizadora.

\section{Paulo Freire, educador}

Paulo Freire (1921-1997) escreveu nos anos 1960 talvez seu mais famoso livro, a "Pedagogia do Oprimido", referência potente a favor de uma educação para conscientização, libertação e justiça social. Nele, faz um chamamento ao compromisso social do educador, dando um passo sem volta em prol de uma educação crítica e transformadora, de uma educação popular problematizadora e humanizada. A relevância de seu trabalho é reconhecida no mundo todo e, mesmo tendo sido alvo de detração recente por parte de ultraconservadores brasileiros, é considerado um dos maiores e mais importantes educadores do século $X X$.

Hoje, entendo a pedagogia proposta por Freire como uma pedagogia dos silenciados ${ }^{8}$. Faz-se necessário ampliarmos o escopo de seu trabalho de forma

8 Vale a pena fazermos aqui a distinção entre os silenciosos (os que não desejam se pronunciar verbalmente) e os silenciados (aos que a pronúncia verbal não é permitida). Em se tratando de um artigo cujo foco é a dança e seu ensino, vale destacar também que o silêncio nem sempre diz respeito somente à linguagem verbal, mas também à corporal. Nesse sentido, todos e todas que são proibidos, acuados, reprimidos, bulinados e agredidos em seus corpos e/em movimentos são também considerados aqui no grupo dos silenciados e silenciadas. A discussão polêmica da década de 1990 levada pela feminista Elizabeth Ellsworth (1992) sobre o direito ao silêncio quando impera somente o diálogo racional vale a pena ser retomado quando consideramos a dança como uma ação dialógica (vide MARQUES, 2010b; ANTILLA, 2003). a olhar criticamente não somente para os silenciados em função da profunda desigualdade de classes foco do autor nos anos 1960/70 - mas também para outros silenciamentos. Os dias de hoje chamam para um olhar interseccionado que abranja a desigualdade social atravessada e atravessadora das diversidades e diferenças raciais, étnicas, corporais, de gênero, idade, identidade de gênero e orientação sexual.

A necessidade de distanciamento social e a dependência dos meios digitais em função da pandemia da Covid 19 tornou mais visíveis as desigualdades sociais mundiais já existentes, tendo, consequentemente, contribuído para aumentar consideravelmente o número de silenciados no planeta. Sobretudo, a pandemia desvelou antigas estruturas de dominação e poder já há tempos impostas pelo capitalismo, pelo colonialismo e pelo patriarcado no mundo ocidental: a naturalização da exploração econômica, a discriminação racial e a violência doméstica têm sido escancaradas ${ }^{9}$.

Por fim, ecoo aqui Moacir Gadotti que já em 2002 enfatizava que o trabalho de Paulo Freire é extremamente relevante para aqueles que talvez não sejam oprimidos ou silenciados, mas que são comprometidos com a justiça social.

Acredito que os referenciais freirianos para uma educação crítica e problematizadora podem nos oferecer lentes para uma nova/outra compreensão da realidade e estabelecer parâmetros diferentes de diálogo e colaboração entre seres do planeta. Sob uma ótica expandida das concepções freirianas para educação, processos de criação e ensino de dança podem ter nesse momento histórico um potente papel no processo de compreensão crítica, problematizadora e sensível da nova realidade que se apresenta.

\section{Laban, artista}

Rudolf Laban (1879-1958) teve um vasto e fértil trabalho desenvolvido e desdobrado em uma Europa atingida e transformada por duas guerras mundiais,

9 Vide Santos (2020), para ampliação do tema. 
uma crise econômica de proporções até então inigualáveis e uma sociedade abalada pela explosão das vanguardas estéticas. Laban propôs parâmetros de experiência e criação em dança que até hoje chacoaIham concepções e posturas rígidas e controladoras em relação aos corpos que dançam: a meu ver, Laban deu um passo sem volta para que criadores e professores de dança se apropriassem de seus lugares de movimento/corpo numa perspectiva libertadora.

O trabalho de Laban pode ser considerado um divisor histórico na dança ocidental sob vários aspectos, principalmente no que diz respeito a uma nova rede de comportamentos, relações e concepções de arte e sociedade no hemisfério norte. A Arte do Movimento de Rudolf Laban quebrou paradigmas, expandiu fronteiras e propôs novos olhares e práticas não só para dança cênica, mas para o movimento humano de modo geral.

Em 1950, Laban lança seu mais conhecido livro no Brasil, "Domínio do Movimento", aqui publicado em 1978, com apresentação de Maria Duschenes. Laban, no prefácio da primeira edição desse livro, afirma que "a fonte da qual devem brotar a perfeição e o domínio final do movimento é a compreensão daquela parte da vida interior do homem de onde se originam o movimento e ação" (LABAN, 1978, p. 11). O autor enfatiza que a dança é uma premência interior do ser humano e que o estudo/investigação do movimento pode gerar conexões entre vida, arte e espiritualidade.

O trabalho de Laban alterou drasticamente os rumos das propostas estéticas da dança da época e abriu possibilidades para outra forma de fazer/pensar dança: rompe de forma radical com as amarras de uma dança cênica ocidental codificada até o início do século XX, tanto nas propostas de geração e pesquisa de movimento quanto nas propostas sonoras e espaciais da dança oficializada nos teatros. Paralelamente a seu trabalho artístico, Laban concebe formas de educação em e por meio da dança até então impensáveis. Seus estudos e propostas fornecem até hoje parâmetros importantes para construção de conhecimento em dança nas mais diferentes situações e territórios de ensino e aprendizagem ${ }^{10}$. Podemos dizer que, quase 100 anos depois do início de suas pesquisas e experiências, o intenso e meticuloso trabalho de Laban de decodificação, análise e sistematização das estruturas de movimento - a Coreologia ${ }^{11}$ - ainda traz contribuições significativas não somente para o campo da arte, mas também da sociologia, psicologia, antropologia, entre outros. Mesmo tendo seus limites, entendo a Coreologia proposta por Laban como uma forma de apropriação da linguagem da dança que nos permite lê-la ${ }^{12}$ de forma ampla, clara, sensível e articulada.

Em pleno século XXI, no entanto, como já havia proposto em meu trabalho de doutorado em 1996, temos de tomar cuidado para não mais compreendermos essa leitura de movimento/ dança, como pretendia Laban, como uma leitura universal das possibilidades humanas, pois

(...) não podemos deixar de levar em consideração que Laban, homem branco, europeu, heterossexual, [sem] deficiência, nascido no século XIX, imprimiu em suas análises uma visão de corpo, de movimento e dança indissociáveis de sua condição pessoal, cultural, histórica e social e, portanto, particularizada. A bandeira da leitura universal de movimento clamada por Laban estaria hoje não somente indo de encontro às vivências e concepções de corpo/movimento da sociedade atual mas também comprometendo uma proposta de educação contemporânea que valoriza a diversidade de interpretações, a multiplicidade de leituras, a polifonia de vozes. (MARQUES, 1999, p. 86).

Diante da crise mundial que nos assola, os referenciais de Laban para leitura de movimento/dan-

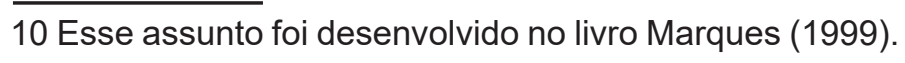

110 trabalho de Laban tem diferentes abordagens e nomenclaturas e pode ser classificado de muitas formas. Não abordarei essa questão nesse artigo, utilizando-me do termo Coreologia por ser o que uso como base para meu trabalho artístico e pedagógico. Vide Scialiom (2017) sobre as diferentes vertentes e desenvolvimentos do trabalho de Laban.

12 Vide Marques (2010a) para discussão mais aprofundada sobre dança, linguagem e leitura. 
ça - e a possibilidade de estendê-la para leituras de mundo, como veremos a seguir -, ainda podem contribuir para não cairmos ingenuamente nas malhas de políticas frívolas e descomprometidas. As referências e o leque de possibilidades para compreender, sentir e pensar os movimentos humanos propostas pelo autor podem se tornar um potente parâmetro - não necessariamente o único - para não nos deixarmos levar por movimentos massificantes e apaziguadores de resistência e visões ingênuas de mundo ${ }^{13}$.

Veremos a seguir algumas formas de diálogo possíveis entre Laban e Freire lançando pontes entre seus tempos históricos e o momento atual de transições planetárias. Para isso, farei um recorte a partir das convergências filosóficas dos dois autores diante de concepções de educação, arte e sociedade.

\section{-Freire e Laban, educação, comunhão e mundo}

Os homens [pessoas] se educam em comunhão, mediatizadas pelo mundo.

(FREIRE, 1983, p. 79, ênfase minha).

Debruço-me nesse artigo, por escolha pessoal, sobre duas palavras/conceitos que, trazidos por Paulo Freire na sua pedagogia do oprimido, geram fontes para a proposta de educação libertadora por ele defendida: são elas, comunhão e mundo. Paulo Freire (1983) entende que "os homens [pessoas] se educam em comunhão, mediatizados pelo mundo" - (FREIRE, 1983, p. 79, ênfase minha) ${ }^{14}$. Comunhão e mundo são também conceitos edificantes do trabalho artístico/educacional de Laban, e, a meu ver, dialogam com os epicentros da crise planetária que nos atravessa hoje.

Aqueles que já perceberam que a sociedade tecnopatriarcal neoliberal está apresentando seu atestado de óbito estão sendo chamados para uma

13 Não me deterei aqui sobre as formas de consciência ingênua e crítica do mundo propostas por Paulo Freire. Para isso vide Freire (1979).

14 Vale observar que a citação é de 1968, quando da primeira edição de Pedagogia do Oprimido. A citação, no entanto, foi retirada da 13a. edição desse livro, em 1983. nova forma de revolução. Essa nova revolução teria como princípio a solidariedade e a comunhão, revisitados por uma visão contemporânea de coletivo. Essa 'revolução solidária' aponta para construção de outro mundo que possa ser reabitado a partir de outros valores e concepções de vida em sociedade.

Busco aqui fazer uma revisão inicial das ideias sobre educação, comunhão e mundo para nutrir esses diálogos que proponho, desde 1991, entre Freire e Laban. Com isso, espero forjar encontros que nos levem a indagações e propostas iniciais para construção de processos de criação/ ensino de dança em prol dessa revolução solidária.

Primeiramente, a citação acima nos chama a refletir sobre o que é educar em comunhão, conforme nos propõe Freire. Do latim communis, chegamos a "comum" em português. A educação em comunhão implica, portanto, em seu sentido original, mutualidade, interrelação, encontro. Educar em comunhão, na concepção freiriana (1983), significa, portanto, "educar com" e não "separado de", como eram compreendidos os processos de ensino e aprendizagem na época em que Freire propõe uma pedagogia para os oprimidos.

Podemos também ampliar o conceito de comunhão dentro dessa perspectiva cunhada por Freire trazendo a força histórica da comunidade e das redes de conexões nela implicadas nos processos da educação, portanto de artes, emancipatórias. A noção de comunidade trazida pela literatura feminista, por exemplo, em especial dos anos $1980 / 90^{15}$, reforça a noção de que experiências em comum nos processos de educação são constituídas à medida que o conhecimento é também compreendido "em relação a", construído coletivamente ${ }^{16}$. $O$ senso de comuni-

15 Vide Shrewsbury (1987), Belenky et al. (1997), Gilligan, 1982, entre outras.

16 A pesquisadora e educadora feminista Susan Stinson (1995) explica que o conhecimento conectado, ao contrário do separado "(...) é encontrado mais frequentemente entre as mulheres, envolve a capacidade de ouvir as vozes do eu e dos outros, tentando perceber o mundo por uma variedade de lentes" (STINSON, 1995, p. 83). 
dade $^{17}$, colocam muitas autoras, repousa justamente na promoção de redes de conexões entre pessoas, acreditando-se que "os indivíduos empoderam as comunidades” (LOMAS, 2007 apud BARR, 2016, p. 10).

É importante no momento de hoje refletirmos justamente sobre o sentido e a importância que há mais de um século se dá à ideia de comunidade em diferentes campos de conhecimento e grupos sociais. A ideia de experiência do comum tem sido compreendida de forma positiva e edificante, mas até hoje tem sido mais uma busca do que uma conquista.

Laban também, à sua maneira e em seu tempo, acreditava que a arte do movimento por ele concebida no início do século XX poderia e deveria ser baseada nos princípios da mutualidade, da colaboração e do trabalho coletivo. Ou seja, Laban, décadas antes, também encampou a ideia de comunidade e comunhão como força motriz positiva dos indivíduos que dançam e que poderiam, de alguma forma, modificar suas realidades.

As Danças Corais (do inglês Movement Choirs) criadas por Laban, por exemplo, ancoram de forma significativa suas intenções artísticas em prol da comunhão. As Danças Corais foram, justamente, germinadas e geradas em uma comunidade artística chamada Monte Veritá, na Suiça, território pacifista, anticapitalista e vegetariano frequentado por Laban nos anos $1910^{18}$.

Laban enfatiza em sua autobiografia que as Danças Corais eram uma proposta de dança comunitária, sem aspirações profissionais, que objetivava formar um coro de dança capaz de, juntos, compartilharem a expressividade dos participantes e a alegria de dançar (LABAN, 1975). Reunindo grandes grupos de pessoas, as Danças Corais tinham caráter celebrativo com o intuito original de fomentar o poder expressivo das comunidades a

17 Shrewsbury (1987) nota que existem três conceitos que são cruciais para a pedagogia feminista: força, comunidade e liderança (STINSON, 1995, p. 82).

18 Vide Preston-Dunlop (1998) para saber mais sobre como o Monte Veritá influenciou de forma decisiva os rumos de trabalho de Laban. partir e por meio da organicidade, dos ritmos próprios e do respeito às identidades dos dançantes. Vera Maletic (1997 apud BARR, 2016) afirma que

Laban concebeu as Danças Corais como um meio que proporciona uma experiência de união, como comunidade através da dança. No entanto, enfatizou que, além da experiência compartilhada do movimento alegre, a tarefa crucial das Danças Corais era manter um senso de humanidade de forma digna. (BARR, 2016, p. 7).

Como exemplo dessa proposta, temos a forma com que autor se referiu à Dança Coral intitulada Titã (de 1927): uma forma de "(...) [visualizar] o espírito da comunidade como um gigante, um Titã que pode e vai quebrar todos os grilhões, e abrir todas as nascentes da humanidade" (LABAN, 1975 apud BARR, 2016, p. 10).

A comunhão desejada nos trabalhos artísticos de Laban traduzia-se, portanto, no ato de "dançar com" - em oposição a "dançar para", como convencionalmente a dança da época era entendida. Em uma Europa cujo cenário era uma praça de guerra, as Danças Corais tiveram especial influência e importância para vislumbrar uma nova possibilidade de vida; possibilitavam experiências de conjunto e de colaboração, que eram, a meu ver, metáforas para uma nova/outra vida em sociedade.

Nesse sentido, a filosofia de fundo do trabaIho artístico de Laban se encontra com os princípios freirianos de comunhão: um encontro da população para construção de grupos potencialmente fortalecidos para lidar com a realidade mais ampla. Para ambos, a comunhão (estendida ao sentido de comunidade) entre as pessoas está ligada à noção de mundo, mas de formas e com ênfases diferentes.

A comunhão/comunidade estão implicadas nos processos artísticos propostos por Laban à medida que vislumbrou a força do encontro de uma dança desligada de passos de códigos, por uma arte potencializada pelo poder criador de seus atuantes. O ideal da transformação social, nesse sentido, seria uma consequência possível da autodescoberta dos dançantes em comunhão. 
Embora possamos encontrar muitos traços diretos de crítica social nos trabalhos artísticos de Laban (principalmente nos trabalhos cênicos dos anos 1920-1930), a potência de sua busca, principalmente quando expande sua arte para educação, estava no fortalecimento, na descoberta e na consciência das possibilidades individuais de cada um (LABAN, 1978). Mesmo dentro de uma perspectiva de conhecimento conectado, a noção de indivíduo em Laban é a que prevalece.

Ao contrário disso, a concepção freiriana de comunhão - e comunidade - está constituída a partir de uma perspectiva social: à ação dos indivíduos se sobrepõe a noção de justiça e igualdade. Freire em seu trabalho não descola o indivíduo da sociedade, mas enfatiza a relação si ne qua non existente entre a educação dos indivíduos e o compromisso social com a realidade (FREIRE, 1979).

Paulo Freire (1983), no entanto, vai além de valorizar a comunhão entre os seres humanos como condição nos processos de relação dos indivíduos com o mundo. O autor alia a "comunhão dos silenciados" aos processos revolucionários de co-laboração ${ }^{19}$. Para o autor, é na comunhão que a co-laboração se torna possível, e não o contrário. Nesse sentido, a força da ação e da mudança não está simplesmente no encontro, mas no que esse encontro pode gerar.

A comum-união freiriana nos instiga a laborar, a trabalhar juntos, ou seja, co-laborar. É a co-laboração, reforça Freire, que permite que “(...) os sujeitos dialógicos se [voltem] sobre a realidade mediatizadora que, problematizada, os desafia." (FREIRE, 1983, p. 198). Ou seja, é a força colaborativa proveniente da união que possibilita a compreensão, a indagação e a ação sobre a realidade opressora que, por sua vez, é mediadora das relações de conhecimento transformadoras.

A formação da comunidade, portanto, não é para Freire um ponto de chegada da ação coletiva; não é a co-laboração que leva à comunhão e, esta, às

19 Utilizo aqui a grafia original do autor (1983) para termo co-laboração. A ênfase estando no "co"-laboração acentua a ideia de parceria, conjunto, união. relações com o mundo, em linha reta. A comunhão é quase uma condição sobre a qual se deve agir para a libertação individual que provém da consciência de si diante das condições opressoras da realidade.

Para Freire, é a comunhão, em estado de co-laboração, que gera a ação dialógica problematizadora do mundo. O autor afirma que "a educação problematizadora, de caráter autenticamente reflexivo, implica num constante ato de desvelamento da realidade" (FREIRE, 1983, p. 80). É na educação problematizadora, finaliza, que a análise crítica sobre a realidade problema é exercida (FREIRE, 1983, p. 198).

Nessa circularidade que envolve sujeitos-realidade-problematização-sujeitos, aparece mais um conceito caro à teoria freiriana: o estar sendo no mundo e com o mundo, a transitoriedade, o inacabamento. Para Freire, "só existe saber na invenção, na reinvenção, na busca inquieta, impaciente, permanente, que os homens [pessoas] fazem no mundo, com o mundo e com os outros. Busca esperançosa também" (FREIRE, 1983, p. 66).

Freire, na sua pedagogia do oprimido, nos convida, já na década de 1960, a compreender o mundo como mediador, em especial, do conhecimento, tal qual enfatizado na epígrafe que abre essa discussão. Freire propõe que a realidade social concreta (mundo) seja interlocutora das relações pedagógicas e, portanto, das interações sociopolítico culturais. Sempre importante relembrar que, para ele, a educação é, declaradamente, um ato político.

As relações entre indivíduos e a realidade sociopolítico cultural tal qual entendidas por Freire não são, como em Laban, uma possibilidade aberta (e fortemente esperada), mas o foco dos processos educacionais. Para Freire, "o mundo já não é algo sobre que se fala com falsas palavras, mas o mediatizador dos sujeitos da educação, a incidência da ação transformadora dos homens [pessoas], de que resulte a sua humanização" (FREIRE, 1983, p. 86).

Resumidamente, poderíamos dizer que Laban concebeu um trabalho cuja proposta é "centrada nos

Marques // Laban e Freire: Entre o velho e o novo mundo Revista Cena, Porto Alegre, $n^{\circ} 32$ p. 157-170 set./dez. 2020 Disponível em: http://seer.ufrgs.br/cena 
indivíduos/pessoas"20 e é a conexão entre elas que potencializa a ação transformadora da comunidade. Por outro lado, compreendo a pedagogia do oprimido como uma pedagogia "centrada na sociedade", pois as relações sócio-político culturais são as formuladoras de redes entre o conhecimento e seus interlocutores.

Aparentemente coincidentes, as visões de Laban e Freire para arte e educação podem colidir dependendo de como são compreendidas e praticadas em contextos de ensino e aprendizagem. A seguir, introduzirei brevemente os conceitos de educação bancária e invasão cultural de Freire para que possamos discutir práticas de ensino de dança que se apropriam do referencial labaniano sem que incidam e/ou reforcem ações que vão contra as expectativas de uma nova/outra forma de organização planetária.

\section{Laban e Freire, educação bancária, invasão cultural e ensino}

A "educação centrada na sociedade" proposta por Freire apoia-se no protagonismo dos educandos no sentido de considerá-los sujeitos de seu pensar e de suas visões de mundo (FREIRE, 1983, p. 141). Paulo Freire esclarece que a educação libertadora se opõe ao que chamou de educação bancária, em que práticas educacionais se apoiam na dominação.

A educação bancária opera por negar o diálogo, deter o conhecimento e mistificar a realidade. Freire aponta que "na visão 'bancária' da educação o 'saber' é uma doação dos que se julgam sábios aos que julgam nada saber" (FREI$\mathrm{RE}, 1983$, p. 67), instituindo uma relação de dominação e desenraizamento dos educandos.

Opondo-se à essa concepção de educação, encontram-se as propostas problematizadoras de Freire para uma educação "...de caráter autenticamente reflexivo [que implica] num constante ato de desvelamento da realidade" (FREIRE, 1983, p. 80). A educação problematizadora é "um esforço permanente através do qual os homens [pessoas] vão per-

20 Vide Marques (1999 e 2010b); Preston-Dunlop (1986) para aprofundamento dessa discussão. cebendo, criticamente, como estão sendo no mundo, com que e em que se acham" (FREIRE, 1983, p.82), adiciona. Enfim, Freire esclarece que "a educação como prática da liberdade, ao contrário daquela que é prática da dominação, implica na negação do homem abstrato, isolado, solto, desligado do mundo, assim também na negação do mundo como uma realidade ausente dos homens" (FREIRE, 1983, p. 81).

Ligadas às práticas de educação bancária está o que Freire chamou de invasão cultural. Esse é um conceito bem amplo e complexo desenvolvido por Freire em toda sua obra em função das amarras colonizadoras e de poder a que, como povo, estivemos e estamos sujeitados. A invasão cultural, afirma, serve à conquista, à dominação e ao silenciamento. Ela é, em última instância, um ato de violência praticado por aqueles que acreditam dominar e possuir o conhecimento e que, em ações antidialógicas, impõem suas visões de mundo "enquanto lhes [aos invadidos] freiam a criatividade ao inibirem sua expansão" (FREIRE, 1983, p.178).

Do ponto de vista freiriano, os invasores culturais instituem sua superioridade, depreciando o que é próprio do outro e que não lhes interessa"21. "É importante, na invasão cultural, que os invadidos vejam a sua realidade com a ótica dos invasores e não com a sua" (FREIRE, 1983, p. 179). Para finalizar, Freire afirma que a "(...) condição básica ao êxito da invasão cultural é o convencimento por parte dos invadidos de sua inferioridade intrínseca" (FREIRE, 1983, p. 179).

Ao aproximarmos Laban e Freire para formularmos propostas de educação em e por meio da dança $^{22}$ é importante situarmos e revisitarmos as teorias e práticas propostas por Laban do ponto de vista freiriano para que não incidamos em práticas bancárias e/ou de invasão cultural. Se tanto Laban quanto Freire acreditavam na liberdade e na liberta-

21 Hoje seria importante ampliar esse conceito para relações de gênero, raça, idade, sexualidade. A violência doméstica contra mulheres, crianças e idosos é um exemplo atual de invasão cultural.

22 Não diferenciarei aqui a educação em e por meio da dança, par isso, vide Marques (1999). 
ção, seria incoerente ensinarmos e aprendermos os princípios de Laban de forma bancária, prestando-nos e/ou permitindo processos de invasão cultural - da Europa do século XX para o Brasil do século XXI.

Conforme já pontuei nesse artigo, a voz que nos chega de Laban é uma voz de homem, cis, europeu, branco, heterossexual, sem deficiência física, de família aristocrática, que empreendeu seu trabalho na primeira metade do século XX. Obviamente, as teorias e práticas propostas por Laban estão impregnadas dessas características que o permitiram ter apenas uma visão parcial do movimento humano e da dança - e não uma proposta universal como por ele alegada (vide MARQUES, 1999). Caso sejamos ingênuos (no sentido freiriano) em relação a isso, incidiremos, paradoxalmente, em uma educação bancária e culturalmente invasora. Ou seja, dependendo de como forem ensinados, os princípios de Laban, que tinham como proposta a liberdade, podem se tornar grilhões.

A grande contribuição de Freire para a educação mundial se dá justamente em propor caminhos para que a educação bancária e a invasão cultural sejam superadas. Isso se dá, resumidamente, a partir de processos de conscientização, problematização, dialogicidade e crítica. A meu ver, a menos que os referenciais de Laban sejam contextualizados e problematizados, continuarão servindo a práticas colonizadoras de desenraizamento e opressão social.

Desde 1996, trabalho com essa perspectiva de contextualização e problematização como vertentes para o ensino de dança. Os ensinamentos de Laban fazem parte dessa proposta, mas não são o foco do trabalho. Nesse trabalho, acrescento às propostas freirianas a articulação e a formação de uma rede de saberes não hierárquica que possibilitam ampliar as formas de diálogo entre a arte, o ensino e a sociedade. Essa proposta pedagógica, chamada "Dança no Contexto", é o ponto de partida para a discussão que proponho a seguir.

Nesse artigo, deter-me-ei aos princípios de problematização e crítica propostos por Freire jogando um olhar pessoal para o ensino de dança enraizado no corpo pelas propostas de Laban.
Desse modo, espero desatrelar os conceitos de Laban de uma educação bancária e atribuir a seus ensinamentos outras possibilidades que não corroborem com a invasão cultural. Pretendo com isso abrir espaços de criação e subjetividades para o ensino de dança e atrelá-lo a possibilidades de conexão com as questões sociais que nos assolam.

Inicialmente, considero importante, como já disse, relativizarmos as leituras que Laban traz do movimento humano, deixando espaços para ampliações, revisões, aprofundamentos de acordo com contextos espaço temporais diversos. Tomar Laban como a última e única palavra para análise e leitura da dança e do movimento pode silenciar outras formas e olhares para a dança em geral.

Ainda, se entendermos as propostas de Laban como subtextos da dança e não como um "tipo" ou classe de dança, poderemos também entender que suas leituras são estruturadoras do dançar e não conteúdos a serem depositados sobre os corpos dos estudantes e/ou artistas. É comum dizermos que temos uma "dança/aula Laban", quando na verdade, a maioria dessas aulas são aulas de repertório, técnicas e/ou criação que tomam como estruturadores os princípios de Laban. Sinteticamente, os elementos estruturais da dança organizados por Laban (a Coreologia, ou os subtextos da dança) podem ser ensinados a partir de (um repertório, por exemplo) e ao mesmo tempo estimular processos de dança (composição ou improvisação).

Reafirmo aqui a necessidade de compreendermos os ensinamentos de Laban não como um "pacote pedagógico", mas sim como uma rede de signos que estruturam a linguagem da dança. É comum entendermos Laban como propositor de um método, metodologia ou proposta pedagógica. De fato, embora tenha tido seu modo próprio de ensinar, seu legado não se encontra na $\mathrm{Pe}$ dagogia, mas sim em sistematizar e organizar princípios que regem a dança e o movimento humano dentro de seu escopo socioafetivo-cultural.

No sentido do já exposto, problematizar contextualizando cultural e politicamente conceitos de corpo, 
dinâmicas, ações, forma etc. formulados por Laban nos possibilitaria permitir diferentes leituras da dan$\mathrm{ça}^{23}$. Perguntar como, se, onde, quando, quem, em que situações e principalmente porque esses elementos fazem parte (ou não) de determinados contextos sociopolítico-culturais é uma forma de problematizarmos esse conhecimento. Quando problematizada, a Coreologia de Laban pode ser impregnada de sentidos, pois cria elos com as realidades polifônicas dos estudantes e dos artistas que com ela trabalham.

Ainda, podemos ampliar de forma aberta e intencional esse trabalho de leitura problematizada dos elementos estruturais da dança para que possamos ter múltiplas leituras de mundo ${ }^{24}$. Parafraseando Paulo Freire, para fazermos da leitura da dança possibilidades de leituras de mundo e vislumbrarmos, de fato, uma arte que dialoga com seus tempos.

Vale destacar que, incluir nas aulas e processos de criação em dança o princípio de ação dialógica tão caro e parte intrínseca da pedagogia do oprimido permitiriam que as propostas de Laban fossem aprendidas sem o estabelecimento de relações autoritárias de saber que alimentam a invasão cultural. Esse é um grande desafio, estabelecer diálogos verbais e corporais nas aulas de dança que permitam diferentes perspectivas e modos de dançar - criar danças.

Finalmente, o grande desafio que se coloca para profissionais da dança é como trazer para o corpo que dança e para o corpo na dança os princípios freirianos de dialogicidade e problematização, para que não sejamos cúmplices da linguagem verbal ao dançar. A corporeificação do diálogo e da pergunta nos processos de problematização podem estabelecer outros vínculos entre participantes que se educam em comunhão, mediatizados pelo mundo.

23 Para ampliar e aprofundar essa discussão, vide Marques (1998, 2007, 2010ab).

24 Para ampliar e aprofundar essa discussão, vide Marques (2010b).

\section{Laban e Freire, o velho novo mundo}

Não me cabe nem me agrada a futurologia, mas sim a constatação de que, se quisermos de fato dar uma guinada nos modos existentes de vida planetária em função das novas configurações sociais que se esboçam, teremos também de ressignificar os focos de interesse dos diálogos aqui propostos entre Laban e Freire. Proponho lançarmos um novo olhar, mesmo que embrionário e rápido, sobre a noção de indivíduos/sujeitos e comunhão lançadas anteriormente nesse artigo a fim de inserir os dois autores aqui discutidos nos processos de passagem e um (já) velho para um novo mundo.

Inicialmente, a fisicalidade e a presença dos indivíduos/sujeitos que eram praticamente uma condição para Laban e Freire na formação das comunidades (de festividades, de saber, de revolução) já foram drasticamente alteradas. É notório que

Hoje, estamos passando de uma sociedade escrita para uma cibersociedade, de uma sociedade orgânica para uma sociedade digital, de uma economia industrial para uma economia imaterial, de uma forma de controle disciplinar e arquitetônico, para formas de controle microprotético e mídia-cibernético. (PRECIADO, 2020, p. 6).

Nessa perspectiva, Paulo Preciado define de forma aguda e precisa que, alinhada e intrínseca a essa grande transmutação do conceito de sociedade (lembrando que "sociedade digital" não exclui, necessariamente, a presencial), a ideia de sujeito/indivíduo também é outra, ou seja,

o sujeito do tecnopatriarcado neoliberal que o Covid-19 fabrica não tem pele, é intocável, não tem mãos. Ele não troca bens físicos ou toca moedas, ele paga com cartão de crédito. Não tem lábios, não tem língua. Ele não fala ao vivo, ele deixa uma mensagem de voz. Não se reúne ou coletiviza. Ele é radicalmente individual. Não tem rosto, tem uma máscara. Seu corpo orgânico está oculto para existir após uma série indefinida de mediações semi-técnicas, uma série de próteses cibernéticas que servem 
como máscara: a máscara do endereço de email, a máscara da conta do Facebook, a máscara do Instagram. Não é um agente físico, mas um consumidor digital, um teleprodutor, é um código, um pixel, uma conta bancária, uma porta com um nome, um endereço para o qual a Amazon pode enviar seus pedidos. (PRECIADO, 2020, p. 9).

A discussão sobre a imaterialidade dos sujeitos ou como as tecnologias transformaram radicalmente as redes de relações humanas e sociais já não é necessariamente nova, mas até então, ouso dizer, não tinham sido de fato assimiladas pela grande maioria da classe artística da dança e/ou meios educacionais. No entanto, a inserção digital quase que imposta no período da pandemia alterou drasticamente esse cenário: o uso das tecnologias foi disseminado e está sendo testado em grande escala e, certamente, já alterou formas e percepções de corpo, espaço, tempo, e, consequentemente, de educação e dança ${ }^{25}$.

A partir disso, teremos de propor novos diálogos entre a dança e a educação pautados não pelo aprendizado do manejo das técnicas de gravação e/ou das plataformas digitais, mas sim pelo que elas alteraram em nossas formas de vida, corpos, maneiras de fazer pensar dança e construção de saberes. Resta-nos perguntar, quais serão as contribuições de Laban e Freire para essa nova/outra realidade instaurada?

Vejo também que as relações entre indivíduos e mundo inseridas na estrutura da comunidade (e da comunhão) do ponto de vista de Laban e de Freire talvez não deem mais conta de abarcar os dilemas e inquietações de um mundo em franco colapso.

Cada um a seu modo, tanto Laban quanto Freire se apoiam na força do grupo como irradiador e detonador de novas/outras relações sociais. Abraçam essa proposta apaixonadamente, com fé e esperança já na primeira metade do século XX. Após quase

25 Essa alteração de modos de vida pela expansão dos meios digitais nas vidas das pessoas se deu, inclusive, pela privação desses meios. Aqueles que por desejo ou pelas contingências de desigualdade social não se apropriaram desses meios também estão sendo transformados, mesmo que indiretamente.
100 anos, temos de reconhecer que os caminhos e concepções de comunhão e comunidade idealizados por Laban e, posteriormente Freire, de certo modo faIharam em se impor como ideais coletivos, em transformarem-se em políticas e dinâmicas econômicas que pudessem modificar a sociedade em uma escala que fizesse diferença em termos globais. Em vez de grandes comunidades igualitárias e autossustentáveis, o neoliberalismo se impôs, acentuando o caráter colonialista e patriarcal de nossos tempos (vide SANTOS, 2020). Onde falharam? Onde falhamos?

Essas perguntas me levaram a uma investigação inicial sobre a formação e conceitos de comunidade que me possibilitou, mesmo que de forma embrionária, revisitar os conceitos de comunhão e comunidade tão caros a Laban e Freire. Não tenho intenção aqui de esgotar o tema, pelo contrário, o intuito desse artigo é apenas levantar questões e apontamentos que possam nos auxiliar a repensar novos diálogos entre dança e educação.

O filósofo italiano Roberto Esposito, já em 1998, trazia um conceito de comunidade que vai, aparentemente, no sentido oposto ao de Laban e Freire. Seus estudos não enaltecem a comunidade, muito pelo contrário, apontam para possíveis causas, vamos dizer, do "fracasso" desse ideal de libertação que está pregado às práticas e ideais comunitários do século $\mathrm{XX}$, incluindo aqui as causas labanianas e freirianas.

O autor nos lembra que a origem da palavra comunidade (communitas) vem de munus, obrigação de dar, pagar encargo. Desse modo, comunidade não estaria associada à ideia de identidade comum (no sentido positivo), pois os indivíduos não se reconhecem como semelhantes, mas são, sim, unidos pelo ônus do tributo devido (vide NEVES, 2017).

Ao contrário do ideal quase romântico de comunidade de Laban em que a força interna dos indivíduos criaria comunidades transformadoras, a definição de comunidade de Esposito coloca em risco, justamente, a identidade individual. Para ele, a comunidade não é a propriedade e sim a impropriedade que liga os indivíduos da mesma. Resumidamente, a comunidade se assenta sobre um 
negativo, pois a obrigatoriedade do tributo anula a individualidade (NALLI, 2013). Mais além, o autor desafia as noções de comunidade como "união e unidade de indivíduos", afirmando que partilhar o que nos é comum não é necessariamente viver os vínculos de uma comunidade (vide PINTO, s/d).

\section{Finalizando}

Em um difícil momento para traçar futuros, nada tão atual como a ideia de Paulo Freire quando diz que o mundo está sendo e que somos inacabados. Nesse mundo em construção, alternativas começam a surgir no longo presente perpétuo de uma quarentena estendida e que podem dialogar com as propostas históricas atualizadas dos autores aqui discutidos. Outras formas de pensar e praticar ações comunitárias se apresentam:

O filósofo espanhol Paulo Preciado acredita que é a transformação política, condição para a cura e o cuidado com a humanidade, que nos impele a encontrar e inventar comunidades para além das identidades e fronteiras a que estamos habituados - das fronteiras soberanas à biovigilância cibernética. "Nossa saúde não virá da imposição de fronteiras ou separação, mas de um novo equilíbrio com outros seres vivos do planeta" (PRECIADO, 2020, p. 8), afirma o autor.

Santos, complementarmente, nos convoca a assumir uma posição mais humilde no planeta em que habitamos. Chama-nos a compreender que há muito mais vida no planeta do que a vida humana e que "a defesa da vida do planeta no seu conjunto é a condição para a continuação da vida da humanidade" (SANTOS, 2020, p. 31). Para isso, "teremos de imaginar soluções democráticas assentes na democracia participativa ao nível dos bairros e das comunidades e na educação cívica orientada para a solidariedade e cooperação, e não para o empreendedorismo e competitividade a todo o custo" (SANTOS, 2020, p. 8).

A solidariedade e a cooperação clamadas por Santos já faziam parte tanto dos ideários quanto das práticas propostas, de formas diferentes, como vimos, por Laban e Freire. Hoje, outros ca- minhos devem/podem ser desvelados nessa direção, mas com o cuidado para que não incidamos novamente em modelos que geraram a crise pela qual passamos. Precisamos des-cobrir nossas novas formas de dançar e de educar a partir de referenciais que nos des-liguem do tecnopatriarcado neoliberal e nos re-liguem a outras formas de vida.

Busco na cultura dos povos originários do Brasil esses caminhos, pois, como já nos dizia Freire, temos de enxergar o mundo com nossas próprias lentes: o líder indígena brasileiro Ailton Krenak nos traz outra concepção de comunidade (coletivo) quando nos alerta que humanidade se descolou da Terra, afirma que "as pessoas foram arrancadas de seus coletivos, de seus lugares de origem, e jogadas nesse liquidificador chamado humanidade" (KRENAK, 2019, p. 14).

Caso não nos reconheçamos mais como "pessoas coletivas", coloca, capazes de criar vínculos com referências que não vejam o mundo como mercadoria e a natureza como recurso, entraremos em extinção. Pessoas coletivas, depreendo humildemente das palavras de Krenak, não são indivíduos que preservam suas individualidades e juntas formam um coletivo, mas "pessoas células" que se compreendem todo, indissociáveis da natureza, e "que conseguem transmitir através do tempo suas visões sobre o mundo" (KRENAK, 2019, p. 28).

O Monte Veritá, é aqui!

\section{Referências}

ANTILLA, Eeva. Journey to the unknown: searching for dialogue in dance education. Helsinki: Acta Scenica, 2003.

BARR, Sherrie. Mining Laban Studies as a critical pedagogical praxis. Journal of Movement Arts Literacy, vol. 3, n. 1, 2016.

BELENKY, Mary Field; CLINCHY, Blythe Mcvicker; GOLDBERGER, Nancy Rule; TARULE, Jill Mattuck. Women's Ways of Knowing: The Development of Self, Voice, and Mind. NY: Basic Books, 1997. 
ELLSWORTH, Elizabeth. Why doesn't it feel empowering? Working through the repressive myths of critical pedagogy. In: LUKE, Carmen; GORE, Jennifer. (Orgs.). Feminisms and critical pedagogy. New York: Routledge, 1992.

FREIRE, Paulo. Educação e mudança. $12^{a}$ ed. Rio de Janeiro: Paz e Terra, 1979.

Pedagogia do oprimido. $13^{\mathrm{a}}$ ed. Rio de Janeiro: Paz e Terra, 1983.

FREIRE, Paulo; SHOR, Ira. Medo e ousadia: o cotidiano do professor. $9^{\mathrm{a}}$ ed. Rio de Janeiro: Paz e Terra, 1986.

GADOTTI, Moacir. Paulo Freire e a cultura da paz. Anais III International Meeting Forum on Paulo Freire, Los Angeles. São Paulo: Centro de Referência do Instituto Paulo Freire, 2002.

GILLIGAN, Carol. In a different voice: psychological theories and women's development. Cambridge: Harvard University Press, 1982.

KRENAK, Ailton. Ideias para adiar o fim do mundo. São Paulo: Companhia das Letras, 2019.

LABAN, Rudolf. A life for dance. London: MacDonald and Evans, 1975.

Domínio do movimento. $2^{\mathrm{a}}$ ed. São Paulo: Summus Editorial, 1978.

MARQUES, Isabel. A partnership towards art in education: Approaching a relationship between theory and practice. Impulse, 3(2), 102-119, 1995.

Dance education in/and the postmodern. In: S.B. Shapiro. (Org.), Dance, power, and difference: Critical and feminist perspectives on dance education. Champaign: Human Kinetics, 1998.
- Ensino de dança hoje: textos e contextos. $1^{a}$ ed. São Paulo: Cortez Editora, 1999.

A dialogue between Art and Education: Laban and beyond. In: V. PRESTON-DUNLOP; L. A. SAYERS. (Orgs.). The dynamic body in space: exploring and developing Rudolf Laban's ideas for the 21st century. Alton: Dance Books, 2010a. Linguagem da dança: arte e ensino. São Paulo: Digitexto, 2010b.

NALLI, Marcos. Communitas/Immunitas: a releitura de Roberto Esposito da biopolítica. Rev. Filos., Aurora, Curitiba, v. 25, n. 37, p. 79-105, jul./dez. 2013.

NEVES, Bárbara. A biopolítica em Roberto Esposito: imunidade e comunidades. Complexitas. Rev. Fil Tem, Belém, v.2, p.6-17, jul/dez 2017.

PINTO, Anna. Precisamos repensar a comunidade: Esposito e a communitas. Revista Verso e Arte, s/d. https://www.revistaprosaversoearte.com/precisamos-repensar-a-comunidade-esposito-e-a-communitas-anna-carolina-pinto/. Acesso em: 28 jun. 2020.

PONTUSCHKA, Nídia. (Org.). Ousadia no diálogo: Interdisciplinaridade na escola pública. São Paulo: Loyola, 1993.

PRECIADO, Paulo. Aprendendo com o vírus. Textura Medium, 2020. https://medium. com/textura/aprendendo-com-o-vírus-1f8542d3ed78. Acesso em: 28 jun. de 2020.

PRESTON-DUNLOP, Valerie. A handbook for dance in education. 2nd ed. London: Longman, 1986.

Rudolf Laban: an extraordinary life. London: Dance Books, 1998. SANTOS, Boaventura. A cruel pedagogia do vírus. Coimbra: Edições Almedina, 2020. 
SÃO PAULO, SME. Visão de área de Educação Artística - Documento 5. São Paulo: Divisão de Orientação Técnica, 1991.

SCIALIOM, Melina. Laban plural: arte do movimento, pesquisa e genealogia da práxis de Rudolf Laban no Brasil. São Paulo: Summus, 2017.

SHREWSBURY, Carolyn. "What is feminist pedagogy?" 1987. Women's Studies Quarterly Reprint, 25, no. $1 / 2$ (1997): 166-73.

STINSON, Sue. Uma pedagogia feminista para dança da criança. Pro-posições. Vol. 6 n.3 [18], novembro, 1995.

Recebido: 02/07/2020

Aceito: $29 / 09 / 2020$

Aprovado para publicação:10/12/2020

Este é um artigo de acesso aberto distribuído sob os termos de uma Licença Creative Commons Atribuição 4.0 Internacional. Disponível em: $<$ http://creative commons.org/licenses/by/4.0>.

This is an open-access article distributed under the terms of the Creative Commons Attribution License 4.0 International. Available at: $<$ http://creative commons.org/licenses/by/4.0>.

Ce texte en libre accès est placé sous licence Creative Commons Attribution 4.0 International. Disponible sur: <http://creativecommons.org/licenses/by/4.0>. 